\title{
Implicações da Transformação Digital nos Pequenos Negócios do Ramo Alimentício diante da Pandemia COVID-19
}

\author{
Implications of Digital Transformation in Small Food Businesses Facing the COVID-19 \\ Pandemic
}

\author{
Jalisson Tavares Costa, Marcos Antônio de Souza Barbosa, \\ Alessandra Cabral Nogueira Lima, Antônio Vinícius Silva Caldas
}

Universidade Federal de Sergipe, Sergipe, Brasil.

\begin{tabular}{l}
\hline I N F O A R T I GO \\
\hline Palavras-chave: \\
Tecnologias em Rede, \\
Mudança Organizacional, \\
Sistema de Delivery, \\
Ramo Alimentício.
\end{tabular}

A R T I C LE I N F O

\section{Keywords:}

Network Technologies,

Organizational Change,

Delivery System,

Food Industry.

\begin{abstract}
RESUMO
A economia passa por constantes mudanças decorrentes da pandemia COVID-19. E, diante das medidas de isolamento social adotadas pelo governo, as empresas classificadas como restaurantes, lanchonetes, pizzarias e outros estabelecimentos de serviços de alimentação e bebidas ficaram impossibilitadas de funcionarem, aderindo à utilização das tecnologias disponíveis. Esta pesquisa buscou analisar as implicações das tecnologias em rede no processo de remodelagem de negócios e no processo de transformação digital dessas empresas. Para alcançar os seus objetivos, foram realizadas entrevistas semiestruturadas com sete empresas. Os dados coletados foram analisados utilizando a Análise Temática, onde emergiram os temas: "Dança dos negócios" e "Contatos não tão imediatos". Dentre os resultados alcançados, notou-se que a tecnologia trouxe vantagens e desvantagens para o processo de remodelagem do negócio de transformação digital. A pandemia COVID-19 atuou como um catalizador externo influenciando na inserção e na valorização da tecnologia no negócio, com ou sem a aceitação dos
\end{abstract} proprietários.

\section{A B S T R A C T}

The economy is undergoing constant changes resulting from the COVID-19 pandemic. And, given the social isolation measures adopted by the government, as companies classified as restaurants, fastfoods, pizzeria and other food and beverage services irritated to function, adhering to the use of available technologies. This research sought to analyze the result of network technologies in the business remodeling process and in the digital transformation process of these companies. To achieve its goals, a semistructured interview was carried out with seven companies. The collected data were using Thematic Analysis, where the themes emerged: "Business dance" and "Not so immediate contacts". Among the results achieved, it was noted that technology brings advantages and disadvantages to the process of remodeling the digital transformation business. The COVID-19 pandemic acted as an external catalyst influencing the insertion and valorization of technology in the business, with or without the acceptance of the owners. 


\author{
Correspondência para autores: \\ jalisson.costa01@gmail.com (Costa,J.T.) (ORCID: 0000-0003-0866-6248), \\ prof.marcosbarbosa@outlook.com (Barbosa, M.A.S) (ORCID: 0000-0002-7225-5382), \\ ale.cnogueira@gmail.com (Lima, A.C.N.) (ORCID: 0000-0002-2519-429X), \\ aulasdefinancas@gmail.com (Caldas, V.S.) (ORCID: 0000-0002-9980-5911).
}

\title{
1. Introdução
}

Com o advento das tecnologias em rede e da geolocalização que caracterizam a atual conjuntura da infraestrutura de tecnologia da informação, micro e pequenas empresas de alimentação e bebidas perceberam a necessidade de modernizar suas regras de negócio utilizando recursos tecnológicos. A Computação em Nuvem, a Internet das Coisas (IoT), os Sistemas Integrados e os aplicativos que se valem da tecnologia em rede são exemplos de recursos resultantes da Quarta Revolução Industrial ou Industria 4.0. A integração das Tecnologias da Informação e Comunicação (TIC) permitem alcançar novos estágios de produtividade, flexibilidade, qualidade e gerenciamento (SACOMANO et al., 2018). Os negócios da atualidade não existiriam sem a tecnologia e a conexão em rede, porque a estrutura é a rede (CASTELLS, 2003) que está presente dos pequenos negócios informais até as empresas de e-commerce ou Fintechs. Vale lembrar que a Internet com todas as possibilidades atuais dos aplicativos de delivery não era prevista quando Manuel Castells (2003) preconizava as empresas eletrônicas. A tecnologia em rede é determinante no mundo dos negócios e muda constantemente a concepção do tempo, do espaço de produção e do trabalho.

A estrutura de organização centralizada e a lentidão no processo de tomada de decisão não condizem com essa realidade volátil. Para o desenvolvimento de uma estrutura organizacional em rede deve-se aderir a flexibilidade, adaptabilidade e rapidez nas respostas em relação às demandas ambientais. Diante do cenário de constantes mudanças, os negócios são atormentados com o aumento da competitividade, expandindo o grau de incerteza estratégica, tecnológica e operacional (SOBRAL; PECI, 2014). Além disso, as novas formas de interação social modificam o relacionamento entre as pessoas (THOMPSON, 2011). "Essas transformações impactam toda a sociedade e descontroem os clássicos modelos de gestão, os sistemas de produção, consumo, logística e distribuição" (MAGALDI; NETO, 2018, p. 40).

A Transformação Digital (TD) trata-se de um processo cultural que deve envolver a participação das lideranças e colaboradores (VERAS, 2019). O papel do colaborador dentro da empresa foi ampliado com o surgimento do empowerment e da liderança. Diante de um cenário externo, caracterizado pela pandemia do COVID-19, organizações em todo o mundo, independentemente de seu porte, precisaram desenvolver novas estratégias para garantir a sua sobrevivência e manterem-se competitivas. De acordo com pesquisa realizada pela MIT Technology Review (CAETANO, 2021), a procura por tecnologia objetivando a TD aumentou. Aproximadamente 45,7\% das empresas brasileiras já estão implementando alguma estratégia de TD, enquanto $30,5 \%$ estão desenvolvendo pelo menos uma dessas estratégias e 1,9\% dos entrevistados não possuem nenhum plano de mudança.

Concomitante a este processo de TD, os empresários se depararam com um conflito político por meio dos decretos que envolveram as três esferas governamentais, vez que tais decretos flexibilizavam as regras de abertura dos negócios e, logo após, lançavam-se novos dispositivos normativos que determinavam o 
fechamento imediato com medidas de isolamento (CÉSAR, 2021). Ante tal cenário, algumas ações foram tomadas pelas empresas, tais como: a adoção de aplicativos de marketplace, prestação de serviços em delivery, criação e ampliação de perfis em redes sociais e ampliação dos canais de atendimento por meio de recursos tecnológicos. Essas intervenções aparentaram ser possíveis soluções e, de certa forma, o surgimento de novas possibilidades de negócios.

Dentre as empresas impactadas com o cenário externo e que buscaram soluções emergentes por meio da tecnologia, foram selecionadas as Micro e Pequenas Empresas (MPES) de Alimentação e Bebidas compreendidas na categoria de: Restaurantes, Pizzarias, Lanchonetes e os Bares/Petiscarias. A cidade escolhida como lócus de pesquisa foi Itabaiana/SE, por ser caracterizada pela presença forte da atividade comercial e, assim como no estado de Sergipe, a cidade teve uma queda considerável em suas atividades econômicas devido às medidas aplicadas por meio do Decreto Estadual n ${ }^{\circ} 40.567$ de 24 de março de 2020 (SERGIPE, 2020) que proibia as atividades presenciais nos serviços públicos e privados. A problemática direciona nosso estudo a respeito das implicações das Tecnologias em Rede na remodelagem dos negócios e no processo de Transformação Digital, durante o período de pandemia, nas MPEs de alimentação e bebidas na cidade de Itabaiana/SE.

O estudo aqui desenvolvido tem como objetivo geral analisar as implicações das soluções baseadas em Tecnologias em Rede na remodelagem dos negócios e no processo de Transformação Digital das MPEs de alimentação e bebidas durante o período de pandemia na cidade de Itabaiana/SE. Para tanto, buscou-se atingir os seguintes objetivos específicos: Identificar as plataformas digitais em rede utilizada pelas MPEs de alimentação e bebidas na cidade de Itabaiana/SE antes e durante a pandemia; investigar as implicações das Tecnologias em Rede na remodelagem do negócio das MPEs de alimentação e bebidas na cidade de Itabaiana/SE, antes e durante pandemia; mapear e compreender os processos de TD das MPEs de alimentação e bebidas na cidade de Itabaiana/SE.

\section{Fundamentação teórica}

\subsection{Tecnologia em Rede}

Existe uma relação profunda entre técnica, cultura e sociedade em relação à tecnologia. Segundo Lévy (2010) as técnicas são produtos da sociedade e de sua cultura desconsiderando que técnicas agem como fator de impacto para a sociedade no geral. Já Tigre (2006, p. 87) encerra que "a tecnologia pode ser definida como conhecimento sobre técnicas, enquanto as técnicas envolvem aplicações desse conhecimento em produtos, processos e métodos organizacionais". O incansável desejo do homem em busca de soluções práticas e tecnológicas para a vida, instiga o desenvolvimento de produtos e artefatos tecnológicos que satisfaçam a sua necessidade do ser humano.

Com o desenvolvimento e o uso das tecnologias nos meios de comunicação, Thompson (2011) afirma que houve a criação de novas formas de ação e de interação no mundo social, surgindo novos tipos de relações e novas maneiras de relacionamento entre as pessoas. Além disso, também é considerado pelo autor que a telecomunicação trouxe uma disjunção entre o espaço e o tempo. Seus estudos indicam que o distanciamento espacial não implica no distanciamento temporal, pois a informação e o conteúdo simbólico podem ser transmitidos por distância e tempo cada vez menores. 
A inserção de tecnologia nos processos das MPES mostrou-se essencial, devido às grandes mudanças no ambiente dos negócios provocados pela instabilidade de fatores ambientais externos e pela competitividade. Do ponto de vista de Laudon e Laudon (2014, p. 83) “os modelos de negócios baseados em rede podem ajudar estrategicamente as empresas a tirar vantagem da economia de rede.".

A cultura empresarial inovou o processo de comercialização ao utilizar a Internet como o canal de comunicação entre a empresa e o consumidor. Para Araujo e Zilber (2013), o comércio eletrônico é uma combinação complexa de processos comerciais, aplicações empresariais e estrutura organizacional proporcionando alterações nas atividades internas da organização. Já as plataformas digitais consistem em plataformas externas baseadas em softwares com base de código extensível que fornece a funcionalidade principal compartilhada pelos módulos que interagem com ela e as interfaces pelas quais eles interoperam (TIWANA; KONSYNSKI; BUSH, 2010). Com o desenvolvimento de plataformas digitais, nasce o mcommerce que pode ser definido como emparelhamento de dispositivos móveis com transações comerciais objetivando a prestação de serviços em qualquer altura e em qualquer lugar por meio do dispositivo móvel com acesso à internet ou ligação wireless (CLARKE III, 2001). O m-commerce contempla a utilização de aplicativos baseados em localização, microtransações e o sistema de posicionamento global (GPS) (LAUDON; LAUDON, 2014).

Com os avanços tecnológicos, surge o marketplace que é definido como uma plataforma virtual destinada a realização de vendas online. Ele é formado por diferentes lojas que anunciam seus produtos, possibilitando que o cliente tenha um leque de opções e tenham facilidade em obter valores mais acessíveis (SAMPAIO, 2018; SEBRAE, 2021a). Uma das vantagens dessa solução é a sua funcionalidade multiplataformas que possibilita o acesso tanto pelo aplicativo quanto pelo navegador.

Outra tecnologia que ampliou a perspectiva do comércio eletrônico, foram as redes sociais. Segundo Recuero (2012, p. 5), as redes sociais são formadas por um conjunto de atores com suas conexões e propriedades, enquanto o sistema vai além da soma de todos esses elementos. Na perspectiva de Junqueira (2008), a sociedade civil contemporânea tende cada vez mais a organizar-se por meio das redes sociais. Essas redes impulsionam o chamado "efeito da rede" que segundo Magaldi e Neto (2018) potencializa o alcance do negócio exponencialmente à proporção que aumenta o número de participantes de sua rede por meio do engajamento, gerando mais conexões e, como consequência, oportunidades de negócios.

\subsection{Remodelagem de Negócio e Transformação Digital}

O processo de elaboração das decisões estratégicas definida por Tigre (2006) orienta a necessidade de definições com base nas percepções de suas forças e fraquezas internas, na intensidade no processo concorrencial e nas características do ambiente econômico nos quais os agentes estão inseridos. Ainda segundo Tigre (2006, p. 216), "quanto mais rígida a estrutura da organização, mais difícil se torna a introdução de mudanças organizacionais". Com as alterações no cenário externo, as mudanças no modelo de negócio são fundamentais para a sua sobrevivência.

Ademais, a remodelagem dos negócios pode ocorrer de forma colaborativa interna ou colaborativa externa, ou seja, a primeira caracteriza-se quando os diferentes setores dentro da empresa passam a agir com maior independência, a segunda ocorre quando duas ou mais empresas associam-se para melhor atenderem 
aos interesses conjuntos. Em ambos os casos, os processos tornaram-se sinérgicos (TIGRE, 2006). Em uma caminhada evolutiva, as pequenas empresas estão se adaptando aos novos cenários e utilizando tecnologia em seu ambiente, tanto nas relações internas quanto nas externas. Com o início da utilização da Tecnologia em Rede, caminha-se no processo de Transformação Digital. De acordo com Veras (2019, p. 40), “a transformação digital está relacionada com as mudanças que as tecnologias digitais podem trazer para o modelo de negócio da empresa, o que implica quase sempre em reconfiguração dos ativos da organização".

\subsection{3. Micro e Pequenas Empresas (MPEs)}

De acordo com o Sebrae (2021b), a microempresa pode ser definida como uma sociedade empresária, sociedade simples, empresa individual de responsabilidade limitada e o empresário, devidamente registrados nos órgãos competentes que aufira em cada ano calendário. Além disso, deve limitar-se a uma receita bruta anual igual ou inferior a $\mathrm{R} \$ 360.000,00$ (SEBRAE, 2021b).

As Micro e Pequenas Empresas (MPEs) possuem um Estatuto Nacional criado por meio da Lei complementar $n^{\circ}$ 123/200 que buscou regulamentar o tratamento favorecido, simplificado e diferenciado a esse setor. Essa lei proporcionou benefícios para os MPE como: simplificação e desburocratização, facilidades para acesso ao mercado, facilidades para a obtenção de crédito e à justiça, estímulo à inovação e à exportação (SEBRAE, 2021b; SHIMA; DALLA COSTA, 2006). As MPEs são organizações que possuem limitações em recursos e capacidades mais restritas (BOUNCKEN; PESCH; KRAUS, 2015). Diante dessas condições, as MPEs apresentam dificuldades em acessar recursos tecnológicos, bem como orientações ao negócio (tanto gerencial quanto comercial). Essas orientações podem ser cruciais para o desenvolvimento da inovação e obtenção de vantagem competitiva. (VASCONCELOS; OLIVEIRA, 2018).

\section{Trabalhos Relacionados}

Em relação a importância do comércio eletrônico, Rezende, Marcelino e Miyaji (2020), explicam a importância do comércio eletrônico no período de pandemia COVID-19, tanto para os autônomos quanto para as grandes empresas. Tais autores afirmam que se faz necessário a construção de estratégias adequadas de modo a aproveitar todas as oportunidades que se emergem no atual panorama.

Por sua vez, Bomfim e Torkomian (2017) destacam em seus estudos que a relação entre as características empreendedoras dos proprietários-gerentes podem afetar diretamente o desempenho das organizações. A forma como está constituído o perfil empreendedor dos proprietários-gerentes compõe uma base sólida que pode permitir às organizações o melhor desempenho de seus processos organizacionais e do negócio em si. As contribuições podem ocorrer na forma de pensar, de agir, de interagir, bem como, no aprendizado com as experiências anteriores.

No estudo denominado "o efeito do uso das mídias sociais e das capacidades dinâmicas no desempenho mercadológico de micro, pequenas e médias empresas" (SANTOS; BEGNINI; CARVALHO, 2019), os impactos das mídias sociais parecem ter mais importância para as pequenas empresas do que para as grandes. Além disso, em tal estudo foi verificado que as empresas tem grandes dificuldades em relação à capacidade de Infraestrutura de TI e à pressão de concorrente social. Tais dificuldades também são verificadas quanto às capacidades de marketing e gerenciamento de inovação. Ocorre que todos esses mecanismos são fundamentais, pois as empresas aprendem a desenvolver competência em redes sociais a partir deles 
(BRAOJOS; BENITEZ; JAVIER, 2015).

Nos estudos de Quelhas (2019), é confirmada a percepção dos empresários de Micro e Pequenas Empresas quanto à relação positiva entre os investimentos em TI e a gestão de clientes no desempenho da organização, mais precisamente envolvendo desempenho em custos, vendas e produtividade. Os resultados encontrados por Quelhas (2019) evidenciam que o principal motivo que leva a MPEs a investirem em Tecnologia da Informação é o desejo de melhor atender seus clientes. Além disso, também reformou a percepção de que a TI auxilia as MPEs na organização de processos internos e nas atividades operacionais, aumentando a capacidade de atendimento.

\section{Metodologia}

Com relação a sua natureza, o presente estudo é caracterizado como uma pesquisa aplicada e exploratória. Nesta pesquisa, foi utilizada a entrevista parcialmente estruturada como técnica de coleta de dados, objetivando obter as experiências práticas dos empresários em relação a utilização de recursos tecnológicos em seus negócios (GIL, 2017; PRODANOV; FREITAS, 2013).

Ao assumir a abordagem qualitativa, adotou-se a estratégia de Estudo de Caso (GIL, 2017), com foco de estudo nas micros e pequenas empresas de alimentação e de bebidas da cidade de Itabaiana/SE. Como técnica de análise de dados foi escolhida a Análise Temática que é caracterizada pela flexibilidade diante diversas abordagens epistemológicas, buscando a essência das experiências do participante, necessitando da interpretação para analisar os dados nos níveis mais implícito e abstrato (BRAUN; CLARKE, 2006; SILVA; BARBOSA; LIMA, 2020).

Para seleção dos casos, primeiramente foi realizada a sondagem em uma amostra não probabilística, definida por meio da acessibilidade com 10 consumidores que pediam lanches e refeições por meio de aplicativos de marketplace com sistema de delivery. Foram reconhecidos dois aplicativos, o "Quero Delivery" e o "Compre Sem Fila". Outros aplicativos conhecidos a nível nacional não foram citados pelos entrevistados, como por exemplo o "iFood" e o "Uber Eats".

Em seguida, os dois aplicativos foram baixados e configurados para que fosse possível acessá-los e listar empresas que utilizam os benefícios do aplicativo. Para se chegar à listagem final, três critérios foram definidos: Ser empresa de alimentação e bebidas (pertencente ao grupo de restaurantes e outros serviços de alimentação); possuir espaço físico para atendimento ou entrega dos produtos produzidos e ter aderido à utilização de tecnologia para o funcionamento do negócio durante a vigência das medidas restritivas adotadas para a contenção da pandemia da COVID-19.

Após a aplicação dos critérios citados acima, foi necessário encontrar o contato telefônico dos responsáveis pelas empresas, pois os aplicativos de marketplace só disponibilizam o cardápio. A maioria dos contatos telefônicos foram encontrados no perfil virtual da rede social Instagram. Em casos de insucesso na busca, foram realizadas pesquisas no site do Google. Em seguida, foi enviada uma mensagem explicativa por meio do WhatsApp juntamente com a carta de apresentação da pesquisa.

Categorias de empresas foram definidas de acordo com o seu ramo de atuação, sendo classificadas como: Restaurante, Lanchonete, Pizzaria e Bar/Petiscaria. A meta definida de entrevistados foi de 02 (duas) empresas por categoria, totalizando uma amostra de 08 (oito) empresas a serem entrevistadas. Contudo, só foi 
possível obter êxito com 07 (sete) empresas, ficando com apenas uma empresa entrevistada na categoria de Pizzaria, devido à dificuldade dos dirigentes de realizar a entrevista remota. As entrevistas seguiram o seguinte roteiro: (1) conhecer sobre a criação da empresa; (2) conhecer o processo de tomada de decisão na utilização de recursos tecnológicos no período pandêmico e (3) identificar as perspectivas futuras em relação às tecnologias utilizadas pelas empresas.

Dentre as limitações no desenvolvimento desta pesquisa, destaca-se:

1. Informalidade dos negócios: muitos empresários não possuem o Cadastro Nacional de Pessoa Jurídica (CNPJ) utilizando o próprio CPF nos cadastros;

2. Entrevistas Remotas: por conta da pandemia COVID-19, as entrevistas aconteceram remotamente e alguns entrevistados tiveram dificuldades com o uso dos recursos tecnológicos;

3. Desconfiança: os empresários são pessoas desconfiadas que não se sentem à vontade em compartilhar informações da empresa, dificultando o acesso de informações importantes para a pesquisa.

4. Indisponibilidade de horário: por conta do contexto pandêmico e com as mudanças nos horários de funcionamentos das empresas houve dificuldade em agendar o horário da entrevista.

\section{Resultados}

Dos entrevistados, 57,14\% alegaram ter criado o negócio por necessidade diante do cenário de desemprego, da falta de renda e das necessidades pessoais. Já 42,86\% dos entrevistados alegaram ter criado de maneira planejada ou adquirido o negócio ao enxergar uma oportunidade de investimento. Em relação ao quadro de funcionário, todas as empresas entrevistadas precisaram reduzir o quadro pessoal devido a proibição de vendas presenciais e a cortes de gastos. As sete empresas apresentaram uma média 46,92\% de demissões em seu quadro. Essas informações estão descritas no Gráfico 1.

Gráfico 1 - Informações sobre a criação da empresa e quadro de funcionários.
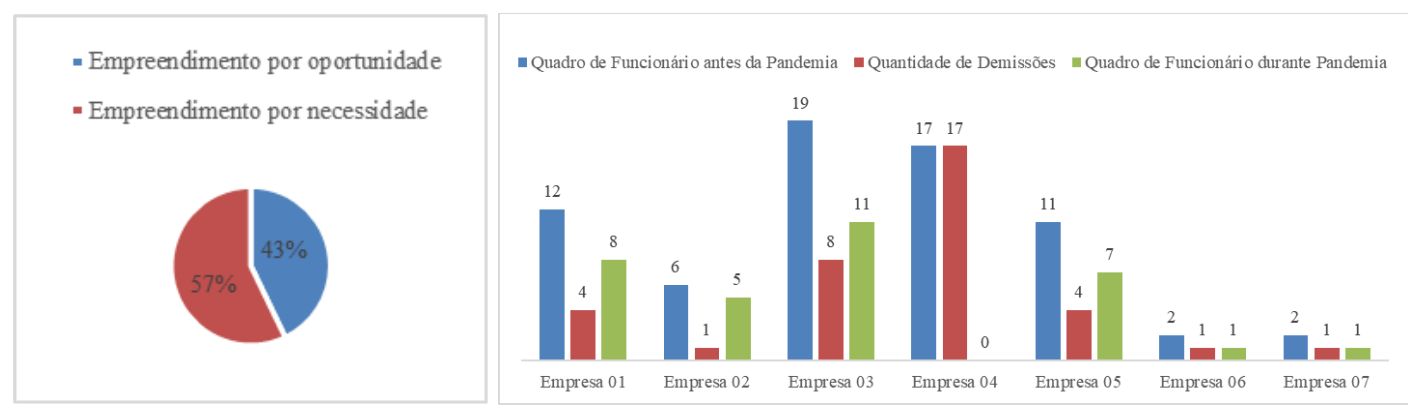

Fonte: Elaborado pelo autor (2021).

Conforme exposto no Gráfico 1, a Empresa 04 demitiu todos os funcionários e iniciou uma reforma em sua estrutura física. A sua pretensão era reinaugurar a empresa após estabilização do cenário pandêmico. Em um total de 36 demissões realizadas nesse período pelas empresas, apenas uma foi solicitação do próprio colaborador (Empresa 7). 
Com o fechamento dos espaços físicos, os entrevistados informaram a necessidade imediata de ampliação dos canais de comunicação com o cliente utilizando os recursos tecnológicos disponíveis no mercado. Algumas empresas já haviam aumentado os canais de atendimento com o objetivo de ampliar o seu público-alvo. Contudo, essa demanda era pouco requisitada. Ao adentrar no cenário de pandemia, referidas empresas se adequaram de modo mais suave ao uso das plataformas tecnológicas. Já as empresas que tinham apenas um canal de atendimento precisaram adaptar-se forçadamente, como foi expresso nos trechos que seguem.

"Não tem comparação entre o atendimento presencial e o
atendimento realizado pelo celular" [Empresa 01].
"A questão não é gostar ou não gostar, precisamos nos adaptar ao
delivery" [Empresa 02].
"Já utilizava o aplicativo, mas sofremos muito quando acabou com
o presencial pois nunca tivemos um fluxo tão grande de atendimento
pelo aplicativo" [Empresa 04].
"Já utilizava o WhatsApp e o Instagram para o recebimento de
pedidos. Não tive problema com a utilização desses aplicativos" [Empresa 06].

“No início sofri muito, você não tem noção com sambamos para dar conta dos atendimentos pois eles chegavam tudo de vez" [Empresa $07]$.

A aproximação da tecnologia de maneira obrigatória criou cenários de conflitos internos gerados pela não aceitação das ferramentas necessárias e pela sobrecarga de atendimentos, tal situação expôs problemas pré-existentes de falhas nos processos e na comunicação interna. Ao se deparar com os diversos problemas organizacionais envolvendo a tecnologia da informação, Laudon e Laudon (2014, p. 20) sugerem a realização de quatro passos para solucioná-los. O primeiro passo é a identificação do problema. Em seguida, a necessidade de propor soluções aos problemas identificados utilizando uma abordagem integrada, envolvendo a tecnologia e o aspecto humano. O terceiro passo é avaliar e escolher uma solução que melhor se enquadre em termos de custos e tempo para desenvolvimento e implantação. A quarta e última etapa refere-se à implantação que é caracterizada pelo delineamento dos novos processos organizacionais e incentivo aos funcionários no processo de adaptações as novas maneiras de condução dos negócios.

De acordo com os trechos citados, nota-se que as empresas que atendiam exclusivamente na modalidade presencial tiveram maiores dificuldades no processo de adaptação ao negócio. Entretanto, isso não implica dizer que empresas que utilizavam outros canais de atendimento, não passaram pelo processo de adaptação ou que tiveram muita facilidade nos atendimentos. Nunca houve tanto atendimento simultâneos de maneira remota como nesse período de pandemia. Por mais que a empresa já tivesse uma familiaridade com as plataformas digitais, houve impacto direto com o fluxo intenso de atendimentos.

Ao questionar sobre quais ferramentas foram utilizadas para a realização de vendas, foram citadas a utilização plataforma de mensagem instantânea, o WhatsApp, aplicativos de marketplace com sistema de entrega (delivery), e as tradicionais ligações telefônicas. A escolha das ferramentas de atendimento foi 
definida com base na perspectiva do dirigente/administrador. As escolhas foram diversificadas, algumas empresas adotaram a maioria das ferramentas citadas, outras aderiram apenas ao atendimento por ligações e pelo WhatsApp e outras realizaram atendimento exclusivamente pelo aplicativo de marketplace com o sistema de delivery.

Dentre as empresas entrevistadas, 71,42\% informaram que utilizavam pelo menos um aplicativo de marketplace antes da pandemia sendo citados os aplicativos "Quero Delivery", "Compre Sem Fila". Desses, o "Quero Delivery" obteve maior destaque por dominar o mercado na região agreste, proporcionando maior visibilidade do negócio e, consequentemente, com aumento do número de pedidos. Houve também mudanças relacionadas com o horário de atendimento. Alguns negócios como o de Bares/Petiscarias funcionam predominantemente das quartas aos domingos, retirando de sua programação as segundas e terças. Contudo, adotando as novas regras na prática, os empresários passaram a enxergar a segunda-feira com outros olhos, aproveitando o dia como oportunidade de prestação de outros serviços. Além disso, todas as empresas decidiram ampliar os seus cardápios, atualizando e em outros casos, inserindo produtos de um novo segmento. A exemplo de Bar/Petiscaria que passou a investir em almoço e café da manhã para suprir a necessidade de determinado público.

"Passamos a oferecer almoço, café da manhã e ainda fazemos lanches na chapa. Mudamos tudo para atender o cliente e para aumentar as vendas. Já tive vontade de vender almoço, mas nunca tive coragem (...) A pandemia fez ampliar o meu negócio" [Empresa 03].

"Meu carro chefe foi sempre o caruru (...) mas desde quando iniciou a pandemia o povo deixou de comprar. Decidimos vender porções de caruru no domingo (...) porções que variam do pequeno ao grande para facilitar as vendas (...) quando divulgava no instagram (...) logo logo vendia todos" [Empresa 02].

"Tive uma queda na quantidade de almoço que fornecia pois os meus clientes estavam trabalhando em casa e agora tinha tempo para fazer a comida (...). Então acrescentei algumas coisas em meu cardápio (...) como salgadinhos, sopas, bolos (...). Eu já fazia bolo, mas as vezes as pessoas não procuravam o bolo inteiro, tipo assim (...) eu fazia uma forma de bolo grande e colocava para dar 06 fatias (...) as fatias que vendesse já estava de bom tamanho para mim. Divulgava as fotos no Instagram e no final do dia, conseguia vender todas as fatias que antes não conseguia" [Empresa 06].

Pode-se dizer que ocorreu uma mudança de paradigma, ao estimular o empresário a pensar em cenários em que antes nunca tinha sido imaginado para oferecer produtos de uma maneira diferenciada. Houve também mudanças em relação a organização das porções, pois, como mencionado, o produto passou a ter mais saída à medida que se fracionou os alimentos, disponibilizando novas opções e novos preços para o consumidor. O sucesso da estratégia do fracionamento esteve diretamente relacionado com a redução do poder 
aquisito dos consumidores que no novo cenário conseguiam comprar os produtos nas porções e preços menores.

As mudanças no padrão de consumo da população implicaram em mudanças nas empresas de alimentação e bebidas. Com uma parcela relevante da população trabalhando em Home Office e com acesso facilitado a cozinha e aos alimentos, a maioria das pessoas foram estimuladas a fazerem suas próprias refeições ao invés de comprá-las. Os recursos desenvolvidos com base na Tecnologia em Rede permitiram a adoção do Home Office, possibilitando ao colaborador a prestação de serviços à empresa de maneira remota e produtiva. Em relação as alterações no padrão de consumo emergidas por esta modalidade de trabalho, o Sebrae (2019) já havia apontado algumas vantagens, dentre elas a tendência à alimentação mais saudável e a redução ao estresse decorrente do trânsito.

Ao adentrar no assunto das redes sociais, as mesmas foram classificadas como primordiais na divulgação dos novos produtos e das mudanças nas porções dos alimentos. O Facebook e o Instagram foram as redes sociais mais utilizadas pelas empresas, sendo considerada como métodos de divulgação rápida e econômica. Todos os entrevistados informaram que realizam a divulgação cotidiana de seus produtos nas redes sociais por meio de publicações, stories e transmissões ao vivo. Mesmo com tamanha facilidade, os empresários destacaram a importância do cuidado com as publicações, pois em determinadas situações, ao invés de colaborarem, poderiam prejudicar a imagem da empresa, conforme os trechos que seguem:

“Aumentamos as nossas publicações no Instagram e criamos uma lista de transmissão no WhatsApp com os contatos de nossos clientes para a divulgação de nossas promoções e produtos. Pagamos um fotografo para tirar algumas fotos profissionais dos pratos para divulgar nas redes socias" [Empresa 02].

“As redes sociais tanto beneficiam quanto causa prejuizo se não for usada da maneira correta. Quando compartilham coisas boas sobre os produtos (...) ela agrega (...). Em contrapartida (...) se algo sair errado... ela destrói tudo rapidamente. É preciso muito cuidado ao se trabalhar com redes sociais (...) Mesmo assim estamos em um periodo que não conseguimos crescer sem a utilização delas" [Empresa 04].

"Nossos clientes são fiéis (...) divulgamos e compartilhamos informações no Instagram, mas não deixei também de divulgar nossa empresa na rádio" [Empresa 01].

"Desde o início da minha empresa que utilizo as redes socais como divulgador de meus produtos. Envio mimos para Digital Influencer para que tenha maior visibilidade e tenha mais seguidores e mais pessoas conheçam minha marca e meus lanches (...) o caminho não é fácil (...) é luta (...) mas se não fosse as redes sociais, muita gente não conhecia meus produtos" [Empresa 06].

Os investimentos nas redes sociais tornaram-se comuns dentro do ambiente empresarial. À medida 
que se ganha experiência ao realizar postagens, divulgação e utilizar a rede ao seu favor, os empresários conhecem o poder da comunicação. $\mathrm{O}$ alcance das redes sociais é adquirido por meio dessas estratégias que atrai o público e os estimula a segui-los. Todos os seguidores das empresas entrevistadas foram conquistados de maneira orgânica, não sendo adquirido por nenhum pacote de anúncio disponibilizado tanto pela plataforma do Instagram quanto pelo Facebook. Essa estratégia de visibilidade nas redes sociais foi definida por Magaldi e Neto (2018) como a nova estratégia atrelada em ganho de escala na nova economia, sendo estimulada pela atuação de um conjunto de diversas plataformas tecnológicas.

Além disso, são adotadas ações de promoção dos produtos em alguns dias da semana que o índice de venda era muito baixo ou simplesmente não existia. Essa ação buscou aumentar a receita e a visibilidade nas redes sociais por meio de engajamentos. Percebeu-se que os canais de divulgações das promoções evoluíram do mundo físico como rádios e carro de som para o mundo virtual com as redes sociais. Sendo assim, houve alteração na percepção sobre a participação da tecnologia no ambiente de negócio. Uma tendência do mundo contemporâneo é o desenvolvimento de práticas de conectividade, por meio do marketing digital. O desenvolvimento de sites, campanhas publicitárias em formatos digitais, inserção nas redes sociais são alguns exemplos de iniciativas do marketing digital que utiliza a convergência tecnológica para reinvenção de determinados tipos de bens e serviços (SOBRAL; PECI, 2014).

$\mathrm{Na}$ análise externa de uma organização, estão presentes as ameaças que foram definidas Oliveira (2015) como variáveis externas que não são controladas pelas organizações e podem não ser favoráveis. Nessa perspectiva, considera-se a pandemia COVID-19 como uma ameaça externa que proporcionou uma série de ondas de mudanças nas regras de negócio de grande parte das empresas. As necessidades como a ampliação dos canais de atendimento, adaptações no horário de funcionamento, adaptações no cardápio, adaptações nas porções dos alimentos, na intensa utilização das redes sociais e promoções, caracterizam como uma verdadeira "Dança nos Negócios" que as empresas realizaram para permanecerem ativas no mercado. Nesse sentido, o tema "Dança nos Negócios" emergiu após a discursão dos autores sobre as mudanças mencionadas pelos entrevistados. Esse tema se posiciona no centro de todas as mudanças conforme apresentado na Figura 1.

Figura 1 - Composição do tema "Dança dos Negócios"

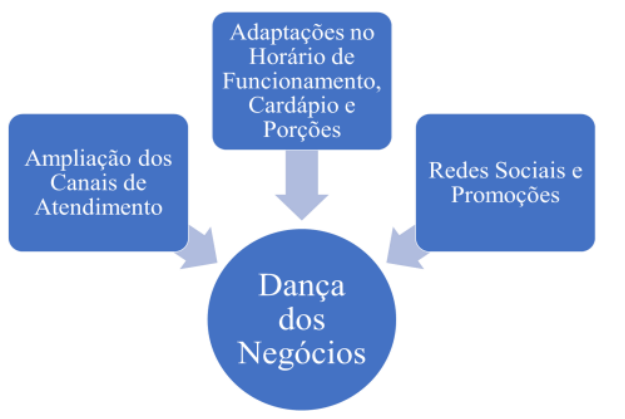

Fonte: Elaborado pelos autores (2021).

Ao se questionar sobre a experiência com a utilização do aplicativo emergiram algumas vantagens e desvantagens. Dentre as vantagens, foram destacadas as possibilidades de analisar os concorrentes de maneira rápida e eficiente, sendo possível ajustar preços e atualizar cardápios. Além disso, o aplicativo traz ferramentas de gerenciamento do tempo, possibilitando a mensuração do tempo médio em atendimentos realizados na 
plataforma. Contudo, a ausência das práticas de métricas acabou gerando conflitos na cultura da própria empresa. Em relação as desvantagens, foi relatado o surgimento de sentimentos negativos, como: ansiedade, fadiga mental e estresse, pelo fato de o tempo ser cronometrado no aplicativo e todos buscarem pela presteza, criou-se um ambiente regido pela pressão, envolvendo todos do processo. Diante dessa situação, alguns empresários expressaram esses sentimentos conforme mencionado a seguir:

"Eu prefiro o presencial, pois o Delivery mexe com o sentimento, com a cabeça da pessoa, cansa mais mentalmente. Eu me senti mais cansada. Trabalhava menos, mas me sentia mais cansada." [Empresa 02].

"Ele trabalha com horas, com tempo, com reclamações (...) e aquilo acaba mexendo com o nosso emocional e o emocional já estava abalado por conta da pandemia." [Empresa 03]

Essa nova estrutura desafiou os empresários a um novo tipo de relacionamento com a produção, pois o tempo de preparo e entrega tornaram-se fatores explícitos de produção. O que antes não era medido e ou gerenciado, passou por a ser exposto em na tela, em números e em reclamações. Segundo Cury (2017), para se compreender um processo de uma organização, primeiramente deve-se conhecer o processo existente, identificar o que ele faz, qual o seu desempenho e quais os seus pontos críticos. Sob uma análise tradicional, um processo deve considerar suas entradas (insumos) e saídas (produtos). É necessário conhecer o processo para consegui-lo gerenciar.

O contato limitado entre empresa e o cliente pela troca de mensagens, provocou a formalização dessa relação dificultando o relacionamento interpessoal entre os envolvidos. Além disso, outros problemas que já existiam nas empresas, foram aflorados diante do cenário pandêmico. Problemas na comunicação, na logística, na divisão do trabalho, na organização das tarefas e inflexibilidade são alguns que dificultaram o processo de remodelagem do negócio. Diante dessas dificuldades de adaptação, foram expressos os sentimentos relacionados a inserção do aplicativo de marketplace em sua empresa das seguintes formas:

"No começo do aplicativo, a gente sambou... não compreendia que tinha que ter um tempo de entrega. A gente sambou, mas foi muito. Teve um dia que deu um desespero aqui porque a gente entregou tudo atrasado, não soube lidar com entrega e aí no outro dia eu parei total no delivery. $O$ aplicativo exigiu e a gente não soube lidar (...). Ai quando a gente colocou a cabeça no lugar, a gente voltou com calma e hoje (...) você não tem noção dos elogios que a gente recebe pela qualidade da comida, pela forma que vai embalado (...)." [Empresa 05].

"Foram tantas dificuldades no início (...) não sabíamos direito como era o funcionamento do aplicativo (...) quebramos muito a cabeça (...) atrasamos muitos pedidos (...) até ir pegando o jeito da coisa. Foi um processo de adaptação. Hoje em dia (...) temos o domínio do aplicativo (...) mas sofremos." [Empresa 07]. 
"Demoramos a pegar o jeito da coisa (...) mas depois de muita dor de cabeça (...) conseguimos dominar o aplicativo" [Empresa 03].

Os empresários tiveram muitas dificuldades ao utilizar a plataforma dos aplicativos de marketplace nos momentos iniciais da pandemia. Foram mudanças rápidas e que necessitaram de respostas rápidas para continuar o fluxo de atendimento. Nessa situação, as empresas utilizaram a estratégia de sobrevivência, definida por Oliveira (2015) como uma estratégia utilizada "quando o ambiente e a empresa estão em situação inadequada ou apresentam perspectivas caóticas" (OLIVEIRA, 2015, p. 197).

Os portais do sistema de delivery possuem interfaces intuitivas que facilitam o processo de aprendizagem e a suas utilizações cotidianas. Contudo, os dirigentes e funcionários não possuem familiaridade com recursos computacionais, pois os seus serviços eram prioritariamente voltados para o contato presencial. Essas dificuldades na utilização do computador somadas à falta de treinamento satisfatório contribuíram significantemente para o surgimento de novos conflitos, falhas nos processos e climas de tensões e estresses. A necessidade de treinamento é vista quando há um distanciamento entre o dever ser e o que é (CHIAVENATO, 2014). À medida que a empresa se adaptava ao processo de utilização da plataforma, o relacionamento com o cliente também passava por mudanças.

Em relação ao retorno dos clientes, as empresas colhiam os feedbacks logo após o processo de degustação e experimentação do produto in loco. Todavia, com o distanciamento físico, o feedback passou a ser registrado no próprio canal de atendimento, seja no aplicativo mensagem instantânea, rede social ou no aplicativo de marketplace na função "Avaliação do Pedido". O que antes era caracterizado como um feedback direto entre o cliente e a empresa, tornou-se público, podendo ser compartilhado em redes sociais ou no espaço público de avaliações do aplicativo de marketplace. Essa exposição da empresa tanto pôde enaltecer quanto desqualificar a imagem das empresas, sendo que foi citada a facilidade de corrigir o erro quando se tem o contato presencial com o cliente, conforme ilustrado a seguir:

"Se tiver um erro no presencial, a gente consegue resolver o problema rapidinho (...) a comida saiu por alguma coisa fria, vai lá e esquenta, traz um mimo para o cliente. Você consegue gerar satisfação." [Empresa 03].

"Sempre procurei saber se os clientes estavam gostando do tempero, se estava gostando do lanche. Foi esse retorno que fez eu consegui a clientela e desenvolver o meu negócio. Quando nos avaliam mal no aplicativo, ficamos tristes pois muitas vezes não tivemos chances de reparar o erro (...) muitas vezes é coisa simples (...) que se resolvia rápido" [Empresa 07].

"Não gosto da forma em que são avaliados os pedidos nos aplicativos. Somos avaliados até por um mal entendido do cliente. Nos esforçamos muito para levar uma comida de qualidade para nossos clientes, e receber críticas agressivas (...) chega bate um desânimo" [Empresa 02].

O relacionamento entre a empresa e o cliente ficou distante com a virtualização do contato, pois o 
cliente não tem mais aproximação com o empresário ou com a equipe de atendimento e torna-se um "juiz" que registra suas reclamações no espaço público do aplicativo para que todos os demais usuários visualizem. percebe-se que "o espaço de manobra está cada vez mais estreito e a criação da vantagem competitiva no negócio requer o desenvolvimento de uma conexão profunda com os consumidores" (MAGALDI; NETO, 2018, p. 185). O líder do negócio deve incorporar a filosofia de aumentar verdadeiramente a perspectiva de conexões de valor com o seu consumidor, gerando um profundo nível de intimidade (MAGALDI; NETO, 2018, p. 189).

Uma outra dificuldade compartilhada pelos entrevistados foi a dificuldade de prover padrão de qualidade dos produtos diante da utilização do sistema delivey e das mudanças nos processos internos. Desde o processo de embalagem até a efetivação da entrega, o produto é diretamente impactado por diversos fatores internos e externos que afetam a preservação da qualidade do alimento. Alguns fatores foram citados como: a temperatura do alimento, a disposição da comida na embalagem, a sobrecarga de pedidos e o tempo de entrega. Esses são alguns fatores comuns que geram registro de críticas no aplicativo por parte do cliente.

No atendimento presencial, o cliente adentrava ao ambiente e tinha consciência da quantidade de pessoas que estavam na fila esperando. Já no aplicativo, o cliente não passou a ter essa noção e acreditava que a empresa estava prontamente à sua disposição para a elaboração do seu pedido. Tal fato gerou frustações quando ocorreram atrasos na entrega com o grande fluxo de pedidos simultâneos. O aplicativo encurtou o tempo e distância, mas provocou o distanciamento no relacionamento com as vendas que só aconteciam, outrora, presencialmente.

A maioria dos entrevistados alegaram a necessidade de reforma na infraestrutura física para realização de atendimentos com qualidade nos momentos de sobrecarga de pedidos. Nos horários de pico, chegavam muitos pedidos de uma só vez e acrescido da pressão do tempo cronometrado aliada ao receio de feedbacks negativos, fizeram surgir várias situações de estresse dentro do ambiente de trabalho. Esse cenário caótico foi propício ao surgimento de falhas no pedido e na entrega.

“Já vendíamos pelo aplicativo antes da pandemia, mas nunca vimos um fluxo tão intenso como nos primeiros dias (...) O computador chegou a paralisar com tanta demanda (...) a impressora não suportava a impressão e falhava... nos momentos de agonia (...) pegava a caneta e o papel e anotava os pedidos (...) cada dia era uma surpresa diferente (...) aos poucos fomos nos acostumando" [Empresa 02].

“Colocamos que estamos abertos no aplicativo... passava um tempo e nada de pedido (...) de repente chegam todos de vez (...) tem momento que chega dois, três, quatro, cinco pedidos de vez, ai é aonde sobrecarrega e ficamos perdidos" [Empresa 05].

"Tem hora que me vejo doida com tantos pedidos (...) tem que ter uma mente muito tranquila para acompanhar a chegada de 10 pedidos de vez e direcionar a fabricação de cada um de maneira correta. Teve um dia que a internet parou do nada (...) fiquei 
desesperada (...) conseguimos resolver o problema roteando internet do celular (...) a vida de aplicativo não é fácil" [Empresa 07].

Além da preocupação em preparar o pedido da forma solicitada e com o padrão de qualidade, os empresários precisaram dar atenção a infraestrutura básica de funcionamento de uma plataforma de marketplace. Tanto os investimentos em TI quanto a sua gestão devem possibilitar a melhoria do desempenho da organização (VERAS, 2019). Esses são alguns requisitos necessários para evitar surpresas durante o pico de atendimento. Todos os empresários se depararam com problemáticas nos momentos de pico de pedidos e foram aplicando as soluções de contorno de acordo com cada situação. Notou-se que existiam duas necessidades latentes para os negócios: investimento de infraestrutura tecnológica e infraestrutura de produção.

As empresas não estavam preparadas para receber tamanha demanda de entregas e necessitaram investir nos meios de transporte ou realizar a contratação de terceiros que se responsabilizassem pelas entregas. Por mais que pareça simples, a organização da logística das entregas interferiu diretamente na qualidade da comida, uma vez que o tempo de duração alterou temperatura do produto. Alguns problemas com a logística foram descritos nos seguintes termos:

“A elaboração das rotas do delivery é bastante complicada pois muitas vezes pegamos pedidos em cada lado da cidade. Esse processo de distância é ruim pois prejudica a qualidade da comida (...)" [Empresa 02].

"E no delivery? O motoboy quebra a moto, o motoboy atrasa porque tem outros pedidos na frente... é muita coisa... É péssimo. Trabalhar com delivery é muito ruim. É uma necessidade que a agente tem que fazer, porque tem que fazer alguma coisa (...), mas não é bom" [Empresa 03].

"São muitos os problemas com o delivery (...) os motoboys não tem cuidado com a moto (...) andam em alta velocidade (...) não tem cuidado com o pedido (...) mesmo orientando (...) eles não têm a mesma responsabilidade. Isso sem falar no risco de assalto (...) ultimamente já assaltaram alguns motoboys que estavam indo realizar a entrega de pedidos" [Empresa 07].

Percebeu-se que o processo de recebimento do produto, da fabricação e da entrega ficou mais complexo, exigindo dos responsáveis resiliência e compromisso. A maioria dos empresários aguardaram ansiosos o retorno da modalidade presencial, não somente para se ter a aproximação com o cliente, mas para diminuir o nível de responsabilidade sobre a qualidade do pedido até o momento da entrega. Em um simples pedido, passou a ser necessária a preocupação com os processos de recebimento, de fabricação, de embalagem, de entrega e com o pós-compra. Além disso, o retorno financeiro na modalidade de delivery é menor que a modalidade presencial, pois para cada pedido houve mais gastos e mais processos concretizados, conforme mencionado nos trechos que seguem.

"O aplicativo ajudou um pouco, mas como não vendia presencial, 
não supre a necessidade. As despesas são grandes pois ainda mantemos os nossos espaços físicos." [Empresa 05].

"Por mais que se tenha picos de solicitação de pedidos, ainda não chega aos pés do atendimento presencial. Conseguimos produzir mais e melhor com o atendimento presencial" [Empresa 02].

"O aplicativo foi o único meio que encontramos para permanecer funcionando. Fomos obrigados a aderir a essa nova forma de atendimento até que essa pandemia seja controlada. Torcemos que em breve estejamos de casa cheia atendendo nossos clientes em nosso espaço" [Empresa 03].

Ao se questionar sobre a perspectiva futura, os empresários expressaram-se da seguinte maneira:

"Com o retorno do presencial, o sistema do delivery cai naturalmente. Não precisa fazer nada. As pessoas gostam e quem o presencial. Assim que for liberado a realização dos atendimentos presenciais, o fluxo de delivery cai." [Empresa 03].

"Torço para que o atendimento presencial retorne e que possamos atender nosso cliente com o padrão de qualidade que sempre atendemos. Pretendemos ficar apenas com os pedidos pelo WhatsApp e por ligação" [Empresa 01].

"Com a liberação do atendimento presencial, os pedidos no aplicativo caem naturalmente pois as pessoas preferem comer e beber aqui presencialmente. É uma forma de entretenimento" [Empresa 02].

"Espero o retorno do presencial par que eu possa reinaugurar meu espaço e voltar com tudo. Estou com uma perspectiva bastante positiva. [Empresa 04].

A maioria dos empresários alegraram que iriam continuar com as tecnologias, pois ao retornar com o atendimento presencial, as solicitações de pedidos pelos aplicativos reduzem naturalmente, vez que as pessoas preferem ir presencialmente até o estabelecimento realizar a compra. As empresas não investem somente na atualização e inovação dos pratos presentes no cardápio, mas em recursos que proporcionam o entretenimento e uma experiência diferenciada ao cliente do início ao final do serviço. Nessa perspectiva, buscam proporcionar um atendimento diferenciado e pratos com qualidade. Em relação a satisfação das necessidades dos clientes, foi mencionado os seguintes trechos nas entrevistas:

"É a questão da satisfação. A gente da [Empresa 03] não vende apenas comida, nós vendemos serviços, geramos satisfação para o cliente, porque comida todo mundo vende. A [Empresa 03] tem esse projeto de vender satisfação. (...) O atendimento é diferenciado, ver o rosto do cliente satisfeito com a comida ou com uma cerveja gelada... isso para a gente não tem dinheiro que pague" [Empresa 
03].

"Pela preservação da sanidade mental (...) a gente leva um pouco de felicidade. A gente é mais do que oferecer a bebida e a comida, a gente leva entretenimento para muitas famílias." [Empresa 04].

Sem o contato físico, as empresas necessitaram investir em outras formas de satisfazer os clientes de modo que obedeçam às regras do distanciamento. Da maneira que foram expostos os comentários acima, notou-se que os proprietários estão ansiosos com o retorno presencial e menosprezam as novas oportunidades diante do novo cenário. Segundo Jones e George (2008), as mudanças organizacionais afetam diretamente o funcionamento organizacional, a cultura, as estratégias, os sistemas de controle, as equipes, a comunicação, a motivação e a liderança. Todos precisam estar prontos para mudanças ao ponto de perceber quando precisam adaptar a sua rotina para reagir a eventos imprevisíveis (JONES; GEORGE, 2008, p. 400).

As empresas estão diante de um período marcado pela implantação de recursos tecnológicos que disponibilizam novas soluções com diversas funcionalidades, mas que no decorrer desta análise temática percebeu-se, na fala dos entrevistados, a dificuldade de se prestar um simples atendimento. A mudança tecnológica oferece tanto a oportunidade quanto a ameaça. Por um lado, ela cria oportunidades. Por outro, pode destruir a demanda de produtos/serviços já estabelecidos (JONES; GEORGE, 2008, p. 400). Por mais que a tecnologia proporcione melhorias significativas em determinados contextos, muitos são os problemas que se afloraram com a implantação repentina desses recursos. E, após análise do cenário de vivências das empresas pelos autores, emergiu o tema "Contatos não imediatos" que faz referência aos impactos do aplicativo de marketplace com o sistema de delivery nas empresas conforme apresentado na Figura 2.

Figura 2 - Subtemas envolvendo "Contatos não imediatos".

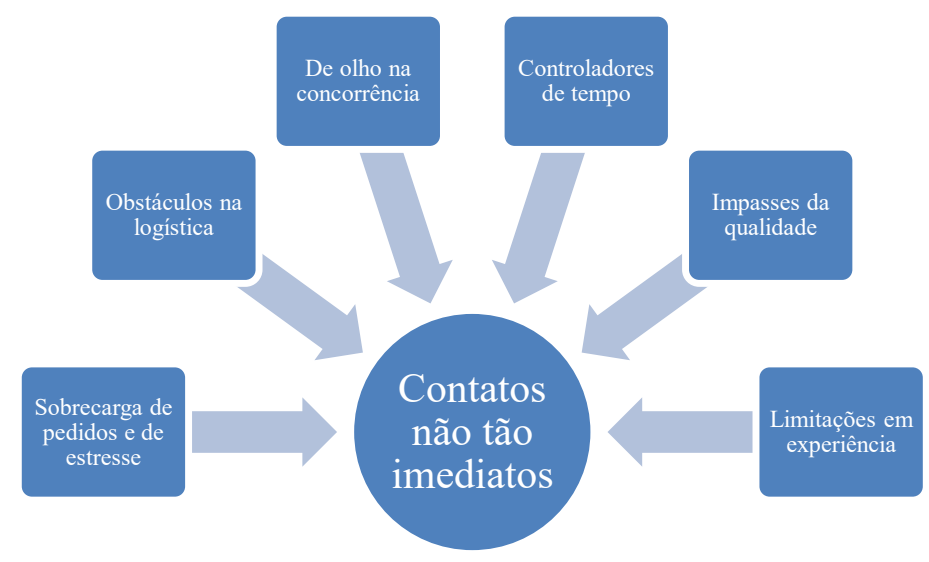

Fonte: Elaborado pelos autores (2021).

\section{CONSIDERAÇÕES FINAIS}

O presente estudo buscou analisar as implicações das soluções baseadas em tecnologias em rede na remodelagem de negócios e no processo de transformação digital das empresas de alimentação e bebidas durante o período de pandemia na cidade de Itabaiana - SE.

Os objetivos específicos serviram para aprofundar os conhecimentos nesta pesquisa. Ao atingir o primeiro deles, foram identificadas as plataformas digitais em rede utilizadas pelas empresas de alimentação 
e bebidas antes e durante a pandemia. Notou-se que as empresas possuíam acesso as tecnologias antes do período de pandemia, mas não davam a devida importância, pois consideravam apenas um serviço incremental.

Com o início da pandemia, a ampliação dos canais de atendimento ao cliente por meio da tecnologia foi fundamental para a continuidade do negócio. Dentre as tecnologias utilizadas, a que mais se destacou foi o aplicativo de mensagens instantâneas, o WhatsApp. Além disso, as empresas passaram a receber muitos pedidos por meio do método tradicional das ligações telefônicas e por meio do aplicativo de marketplace utilizando o sistema delivery. Destacando-se que nenhuma empresa desta pesquisa utilizou outra ferramenta tecnológica para melhoria e resolução de problemas administrativos e de negócio.

O segundo objetivo relacionado com a investigação das implicações das tecnologias de rede no processo de remodelagem dos negócios das empresas de alimentação e bebidas. Percebeu-se que a subcategoria do ramo Bar/Petiscaria teve mais impacto nesse período de pandemia, pois a regra de negócio gira em torno do contato presencial com o cliente, proporcionando momentos de lazer e socialização. O empreendimento que permaneceu aberto, optou por ampliar seu negócio para restaurante, fornecendo cafés da manhã e almoços. Todas as empresas que participaram da pesquisa realizaram ajustes em seus cardápios, investiram em redes sociais e realizaram promoções estratégicas para aumento do alcance de públicos e visualizações. As novas formas de contato com o cliente exigiram novas habilidades e perspectivas buscando satisfazer as expectativas e necessidades de seu público.

O terceiro e último objetivo buscou compreender o processo de transformação digital nas pequenas empresas. Verificou-se que a pandemia impulsionou a entrada da tecnologia nas organizações, mostrando para os proprietários a necessidade de adequar processos e ampliar suas regras de negócio, pois vive-se um período marcado por constantes evoluções tecnológicas e mudanças na cultura da sociedade. Ao ignorar a inserção de tecnologia no negócio de forma proativa, a empresa foi empurrada pela necessidade dos próprios clientes ou por fatores externos incontroláveis. A competitividade exigiu atitudes estratégicas e inteligentes dos administradores para o contínuo posicionamento das empresas no mercado e para a busca por resultados admiráveis (OLIVEIRA, 2015, p. 195). No cenário atual, os entrevistados caminham em passos estreitos nos processos de transformação digital, dando pouca atenção aos benefícios estratégicos que ela pode trazer para a organização.

O presente estudo concluiu que o período da pandemia COVID-19 foi um catalisador externo que influenciou na inserção e na valorização da tecnologia no negócio, seja com ou sem aprovação dos proprietários das empresas. Todos os negócios de alimentação e bebidas prezam pelo contato presencial com o cliente, utilizando-o como estratégia de promover satisfação e novas experiências. Após esse período de pandemia, o empresário terá que escolher se pretende continuar no sistema híbrido (presencial e online) ou somente presencial. Essa decisão mostrará a perspectiva do empreendimento quanto o processo de transformação digital do negócio, pois quando a ideia está amadurecida na cabeça do líder, a inserção de novas tecnologias e mudanças nos processos internos acabam sendo acoplados de maneira sútil. O perfil de líderes é demandado pelo desenvolvimento de novas habilidades para compor o perfil de líder de sucesso na $4^{\mathrm{a}}$ Revolução Industrial (MAGALDI; NETO, 2018, p. 150).

As informações da pesquisa compartilhadas neste estudo trazem uma perspectiva das empresas em 
um cenário com aproximadamente 1 ano e três meses após início da pandemia. Com a continuidade do plano de vacinação organizado pelo Governo Federal do Brasil, em breve a população estará vacinada e as restrições de distanciamento e isolamento social serão flexibilizadas. A realização de estudos futuros sobre essa perspectiva tecnológica em um cenário pós-pandemia é uma possibilidade para a realização de novas pesquisas.

\section{Referências}

ARAUJO, J. B. DE; ZILBER, S. N. Adoção de E-Business e mudanças no modelo de negócio: inovação organizacional em pequenas empresas dos setores de comércio e serviços. Gestão e Produção, v. 20, p. 147 $161,2013$.

BOMFIM, E. DA C.; TORKOMIAN, A. L. V. Entrepreneurial characteristics associated with the performance of micro, small and medium TBFs of the ICT sector in Ribeirão Preto. Revista Gestão da Produção Operações e Sistemas, v. 12, n. 4, p. 128-158, 1 nov. 2017.

BOUNCKEN, R. B.; PESCH, R.; KRAUS, S. ME innovativeness in buyer-seller alliances: effects of entry timing strategies and inter-organizational learning. Review of Managerial Science, v. 9, p. 361-384, 2015.

BRAOJOS, J. G.; BENITEZ, J. A.; JAVIER, F. L. M. How do small firms learn to develop a social media competence? International Journal of Information Management, v. 35, n. 4, p. 443-458, 1 ago. 2015.

BRAUN, V.; CLARKE, V. Using thematic analysis in psychology. Qualitative research in psychology, v. 3, p. 77-101, 2006.

CAETANO, G. Raio-X da Transformação Digital no Brasil em 2021: principais dados e insights. Disponível em: $\quad<$ https://mittechreview.com.br/raio-x-da-transformacao-digital-no-brasil-em-2021-principais-dados-einsights/>.

CASTELLS, M. A Galáxia Internet: reflexões sobre a Internet, negócios e a sociedade. Rio de Janeiro: Jorge Zahar Editor, 2003.

CÉSAR, D. Com confusão de decretos, comerciantes de SP não sabem se abrem ou fecham. Disponível em: $<$ https://economia.uol.com.br/noticias/redacao/2021/03/15/decretos-comerciantes-interior-sao-paulo.htm>. Acesso em: 2 set. 2021.

CHIAVENATO, I. Gestão de pessoas: $O$ novo papel dos recursos humanos nas organizações. 4. ed. Barueri: Manole, 2014.

CLARKE III, I. Emerging value propositions for m-commerce. Journal of business strategies, v. 18, n. 2, p. 133, 2001.

CURY, A. Organizaçao e métodos: uma visão holística. 9. ed. São Paulo: Atlas, 2017.

GIL, A. C. Como elaborar projetos de pesquisa. 6. ed. São Paulo: Atlas, 2017.

JONES, G. R.; GEORGE, J. M. Administração Contemporânea. 4. ed. São Paulo: McGraw-Hill, 2008.

JUNQUEIRA, L. A. P. Gestão Social: Organizações parceria e redes sociais In: CANÇADO, A.C. et al. Os 
desafios da formação em gestão social. Palmas: Coleção Enanpegs, 2008.

LAUDON, K. C.; LAUDON, J. P. Sistemas de informação gerenciai. 11. ed. São Paulo: Pearson Educacion do Brasil, 2014.

LÉVY, P. Cibercultura. 3. ed. São Paulo: Editora 34, 2010.

MAGALDI, S.; NETO, J. S. Gestão do amanhã: tudo o que você precisa saber sobre gestão, inovação e liderança para vencer na 4a Revolução Industrial. São Paulo: Gente, 2018.

OLIVEIRA, D. DE P. R. DE. Planejamento estratégico: conceitos, metodologias e práticas. 33. ed. São Paulo: Atlas, 2015.

PRODANOV, C. C.; FREITAS, E. C. DE. Metodologia do Trabalho Científico: Métodos e Técnicas de Pesquisa e do Trabalho Científico. 2. ed. Novo Hamburgo: Feevale, 2013.

QUELHAS, F. D. C. Impacto dos investimentos em tecnologia da informação nas variáveis estrategicas organizacionais e no desempenho de Micro e Pequenas Empresas (MPE). Revista Gestão e Tecnologia, v. 19, n. 4, p. 138-164, 2019.

RECUERO, R. A rede é a mensagem: Efeitos da Difusão de Informações nos Sites de Rede Social. Lo que Mcluhan no previó, p. 205-223, 2012.

REZENDE, A. A. DE; MARCELINO, J. A.; MIYAJI, M. A reinvenção das vendas: as estratéias das empresa brasileiras para gerar receitas na pandemia de covid-19. Boletim Conjuntura, v. 2, n. 6, p. 41-48, 2020.

SACOMANO, J. B. et al. Indústria 4.0 : conceitos e fundamentos. São Paulo: Edgard Blüche, 2018.

SAMPAIO, D. Marketplace: o que é e como alavancar as vendas por meio de uma plataforma online. Disponível em: <https://rockcontent.com/br/blog/marketplace/>. Acesso em: 28 jul. 2021.

SANTOS, S. S. S. DOS; BEGNINI, S.; CARVALHO, C. E. O efeito do uso das mídias sociais e das capacidades dinâmicas no desempenho mercadológico de micro, pequenas e médias empresas. v. 1, n. 1, p. 105-112, 2019.

SEBRAE. Confira as vantagens e desvantagens do home office. Disponível em: $<$ https://www.sebrae.com.br/sites/PortalSebrae/artigos/vantagens-e-desvantagens-do-homeoffice,78f89e665b182410VgnVCM100000b272010aRCRD>. Acesso em: 8 set. 2021.

SEBRAE. Conheça as vantagens de vender seus produtos em um e-marketplace. Disponível em: $<$ https://www.sebrae.com.br/sites/PortalSebrae/artigos/conheca-as-vantagens-do-e-marketplace-para-ospequenos-negocios,3f6402b5b0d36410VgnVCM1000003b74010aRCRD>. Acesso em: 8 set. 2021a.

SEBRAE. Micro e Pequenas Empresas. Disponível em: $<$ https://www.sebrae.com.br/sites/PortalSebrae/artigos/entenda-as-diferencas-entre-microempresa-pequenaempresa-e-mei,03f5438af1c92410VgnVCM100000b272010aRCRD>. Acesso em: 7 dez. 2021b.

SERGIPE. Decreto $\mathbf{n}^{\mathbf{0}} \mathbf{4 0 . 5 6 7}$ de $\mathbf{2 4}$ de Março de 2020 Disponível em: $<$ https://www.se.gov.br/uploads/download/midia/12/8e27be55ccfddfd7c243b7d57000211c.pdf $>$. Acesso em: 8 set. 2021. 
SHIMA, W. T.; DALLA COSTA, A. Lei Geral da Micro e Pequena Empresa. Revista Economia \& Tecnologia, v. 2, n. 4, 31 dez. 2006.

SILVA, M. R. DA; BARBOSA, M. A. DE S.; LIMA, L. G. B. Usos e possibilidades metodológicas para os estudos qualitativos em Administração: explorando a análise temática. Revista Pensamento Contemporâneo em Administração, v. 14, n. 1, p. 111-123, 31 mar. 2020.

SOBRAL, F.; PECI, A. Administração: teoria e prática no contexto brasileiro. São Paulo: Pearson Prentice Hall, 2014.

THOMPSON, J. B. A mídia e a modernidade: uma teoria social da mídia. Petrópolis: Vozes, 2011.

TIGRE, P. B. Gestão da inovação: a economia da tecnologia no Brasil. Rio de Janeiro: Elsevier, 2006.

TIWANA, A.; KONSYNSKI, B.; BUSH, A. A. Platform Evolution: Coevolution of Platform Architecture, Governance, and Environmental Dynamics. Information Systems Research, v. 21, n. 4, p. 675-687, dez. 2010.

VASCONCELOS, R. B. B. DE; OLIVEIRA, M. R. G. DE. DETERMINANTES DA INOVAÇÃO EM MICRO E PEQUENAS EMPRESAS: UMA ABORDAGEM GERENCIAL. Revista de Administração de Empresas, v. 58, n. 4, p. 349-364, ago. 2018.

VERAS, M. Gestão da tecnologia da informação: sustentação e inovação para transformação digital. Rio de Janeiro: Brasport, 2019. 